\title{
Should I Bike or Should I Drive? Comparative Analysis of Travel Speeds in Montreal
}

\author{
Nicolas Saunier ${ }^{1} \mathbb{D}$, Vincent Chabin ${ }^{1}$ \\ ${ }^{1}$ Civil, Geological and Mining Engineering Department, Polytechnique Montreal \\ Keywords: urban transport, mobility, cars, bicycles, travel speed \\ https://doi.org/10.32866/001c.11900
}

Transport Findings

Travel time remains one if not the most important factor for mode choice.

Cycling is generally considered to be competitive compared to cars in dense urban areas. This paper compares the travel speeds of both modes in Montreal extracted from crowd-sourced trip data. Although car travel is generally faster than bicycle travel, the difference tends to decrease during peak hours or in downtown areas. More than this general difference, travel speed for a significant proportion of cyclists is higher than for the slowest cars. Temporal variation in bicycle travel speed is also smaller than for cars.

\section{RESEARCH QUESTION AND HYPOTHESIS}

Travel time remains one of the most important factors for mode choice (Clarry, Faghih-Imani, and Miller 2019; Mokhtarian and Chen 2004). In dense urban areas cycling is often competitive with driving regarding travel time, and even faster in some cases, especially during rush hour or for short trips (FaghihImani et al. 2017; Jensen et al. 2010). Along with the many health or environmental benefits (Vandenbulcke et al. 2011), this may explain the increase in cycling in cities (McLeod and Murphy 2014). Comparing travel times for different modes is only possible for pre-defined origin-destination pairs, which may not be easily correlated with the possible explanatory factors, especially spatial attributes of roads and cycling facilities (Clarry, Faghih-Imani, and Miller 2019). On the other hand, speeds along a trip can be associated with nearby spatial characteristics and speed comparisons can therefore be done for spatial zones. This paper provides a descriptive comparison of the speed of trips by mode of transportation, in this case by cars and bicycles, and by spatial zone to get a clear picture of their relative spatial competitiveness.

\section{METHODS AND DATA}

\section{The Data}

In this research, the crowdsourced datasets "MTL Trajet" collected by the City of Montreal in Canada and made available on its open data portal were used (Ville de Montréal 2019). These datasets contain trips made in the Greater Montreal Area recorded in the month of October of 2016 and 2017 via a mobile application. Each trip is composed of a series of georeferenced points with timestamp and instantaneous speed (see Table 1 for a sample). Information on the mode of transportation is also provided for some trips. This study focuses only on the trips made exclusively by bicycles or cars. 


\begin{tabular}{|c|c|c|c|c|c|c|}
\hline point_id & trip_id & sequence & mode & $\begin{array}{l}\text { speed }(\mathrm{m} / \\
\mathrm{s})\end{array}$ & timestamp & geometry \\
\hline Oda347dd-72b... & 000041ca-68d... & 0 & car & 14.4 & $\begin{array}{l}2016-10-20 \\
15: 52: 23.00\end{array}$ & $\begin{array}{l}\text { POINT(-73.55301 } \\
45.59863)\end{array}$ \\
\hline $6939 d 470-950 \ldots$ & $000041 c a-68 d . .$. & 1 & car & 16.5 & $\begin{array}{l}2016-10-20 \\
15: 52: 29.00\end{array}$ & $\begin{array}{l}\text { POINT(-73.551976 } \\
45.59816)\end{array}$ \\
\hline a66bcdeb-369... & $000041 c a-68 d . .$. & 2 & car & 15.3 & $\begin{array}{l}2016-10-20 \\
15: 52: 33.00\end{array}$ & $\begin{array}{l}\text { POINT(-73.5513 } \\
45.597833)\end{array}$ \\
\hline f5099a15-57f... & $000041 c a-68 d . .$. & 3 & car & 8 & $\begin{array}{l}2016-10-20 \\
15: 52: 37.00\end{array}$ & $\begin{array}{l}\text { POINT(-73.550715 } \\
45.597561)\end{array}$ \\
\hline
\end{tabular}

\section{Data processing}

To ensure the quality of the data used in the study, two filters were applied. The first checks that each instantaneous speed is smaller than $17 \mathrm{~m} / \mathrm{s}(61.2 \mathrm{~km} /$ h) for bicycles and $45 \mathrm{~m} / \mathrm{s}(148 \mathrm{~km} / \mathrm{h})$ for cars. The second filter verifies the participant's ability to travel the distance between two consecutive points: the Euclidean distance between two points must be smaller than the maximum distance the participant could have traveled during the time interval. This maximum distance is defined by the distance the participant would have traveled with his initial speed $v_{0}$ at instant $n$, an acceleration $a_{\max }$ of $1 \mathrm{~m} / \mathrm{s}^{2}$ and a maximum speed $v_{\max }$ of $17 \mathrm{~m} / \mathrm{s}$ for bicycles or an acceleration $a_{\max }$ of $5 \mathrm{~m} /$ $s^{2}$ and a maximum speed $v_{\max }$ of $45 \mathrm{~m} / \mathrm{s}$ for cars during the interval between instants $n$ and $n+1$ as described in formula (1). If the condition is not satisfied, the position $n+1$ is removed and the same condition is applied to instants $n$ and $n+2$, and so one. After these two filters, the resulting dataset contains 77710 trips ( 17550 by bicycle and 60160 by car).

$$
d_{\max }=\left\{\begin{array}{c}
\frac{1}{2} * a_{\max } * t^{2}+v_{0} * t, t * a_{\max }+v_{0} \leq v_{\max } \\
\frac{1}{2} * a_{\max } * t_{1}^{2}+v_{0} * t_{1}+v_{\max } *\left(t-t_{1}\right), t * a+v_{0}<v_{\max }
\end{array}\right.
$$

where

- $t$ is the duration of the time interval between two points

- $t_{1}=\frac{v_{\max }-v_{0}}{a_{\max }}$ is the necessary duration to reach maximum speed

The units of analysis of the study are Transport Analysis Zones (TAZs) provided by the ministry of transportation (see Figure 1) (mean size of 4.5 $\mathrm{km}^{2}$ ). The mean speed of a trip in a specific TAZ is defined as the average of the instantaneous speeds at each position in the TAZ weighted by the duration between each successive position. If the duration between two positions in the same TAZ is greater than $90 \mathrm{~s}$, the trip was divided in separate trips to separate trip segments of the same participant passing again through the same TAZ. The mean speed of a mode in a TAZ is similarly defined as the average of each 


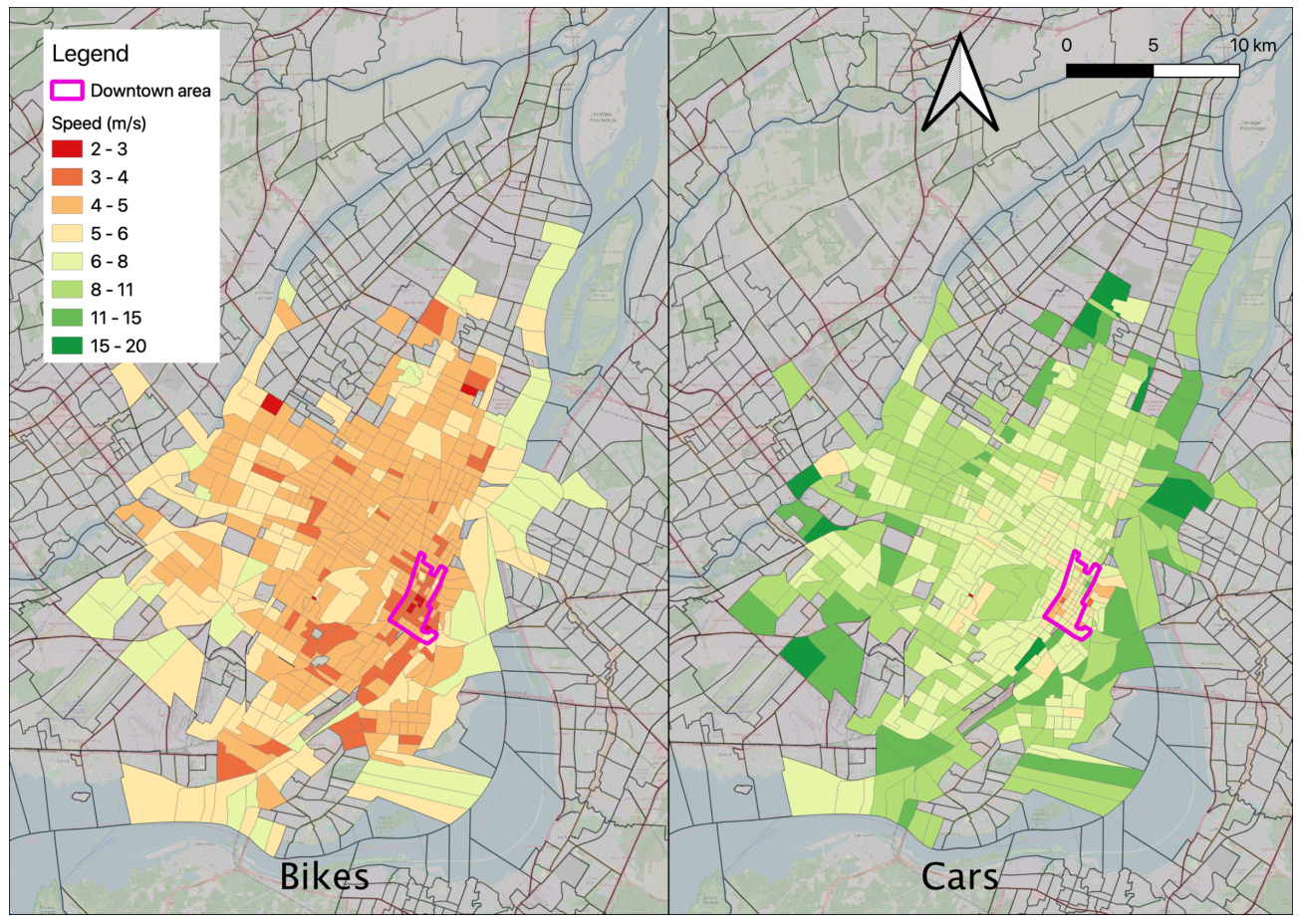

Figure 1 Map of the average speeds of bicycles (left) and cars (right) in each TAZ

trip average speed in the TAZ weighted by the duration of each trip in the TAZ. For statistical reasons, only TAZs with at least 30 records for both cars and bicycles were kept. Overall 546 TAZs met those requirements.

\section{FINDINGS}

Figure 1 shows the average speed of cars and bicycles in each TAZ. For both bikes and cars, the average speed is lower in the downtown area than in the more peripheral areas where data is available. Causes of this may however differ depending on the mode. For cars, lower travel speeds are a consequence of the demand and resulting congestion, but also possibly of the road design (number of lanes, density of intersections, signal timing). These factors along with the cycling infrastructure can also affect the speed of bicycles. Bicycle speeds may also be higher in peripheral areas because the type of riders also differs: for example, riders traveling longer distances tend to be fitter and go faster (Jensen et al. 2010). This spread in speed is more important for cars than for bikes: the mean coefficient of variation of the average speed of each mode in a TAZ is 0.28 and 0.17 for cars for bicycles respectively. The average speeds over the 546 TAZs are $8.8 \mathrm{~m} / \mathrm{s}(31.7 \mathrm{~km} / \mathrm{h})$ and $4.6 \mathrm{~m} / \mathrm{s}(16.6 \mathrm{~km} / \mathrm{h})$ for cars and bicycles respectively.

The Figure 2 shows the relative differences in mean speed between bicycles and cars, relative to bicycles, within each TAZ. Only five TAZs show no statistical difference between the mean oncespeeds of bicycles and cars at the $95 \%$ confidence level (labeled "Non-significant difference" on Figure 2). The relative difference is $50 \%$ or less for $148 \mathrm{TAZs}$, while it is $91.3 \%$ overall. The relative 


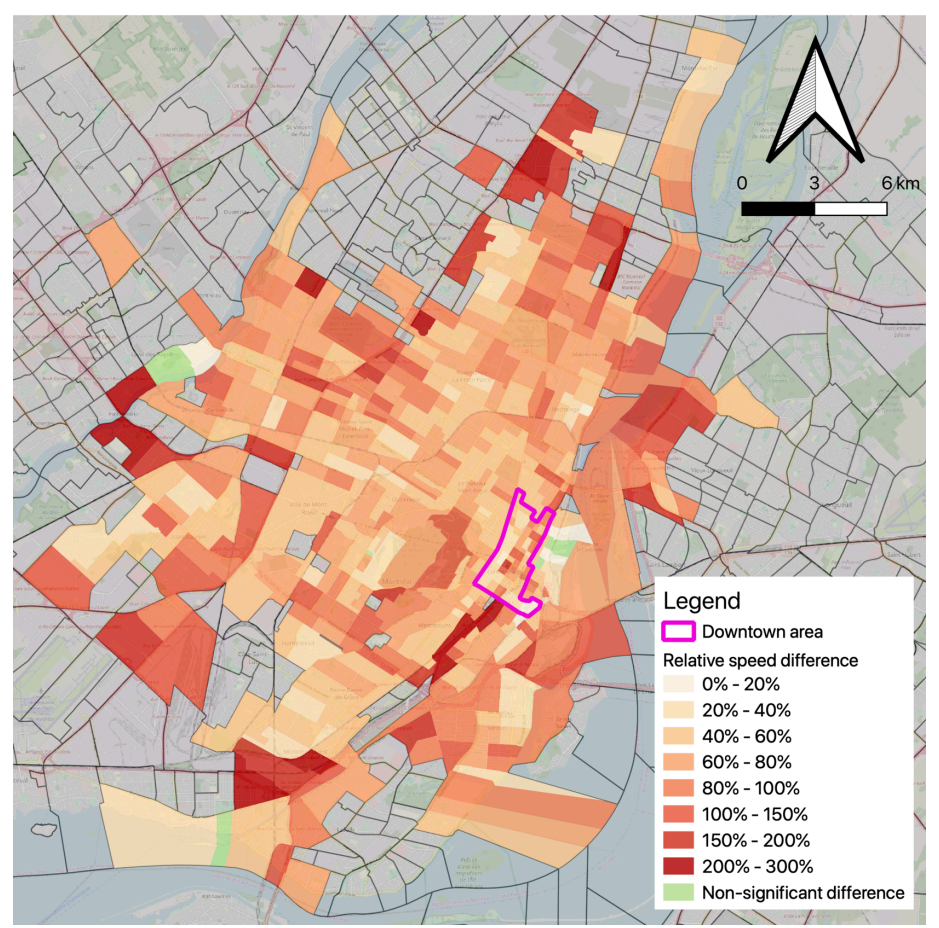

Figure 2 Relative difference in speed between bikes and cars

difference is lower in the downtown area. In this area, the relative difference is $50 \%$ or less in 24 of the 51 TAZs. The TAZs with a relative difference higher than $200 \%$ contain highways. Table 2 shows that the relative speed difference in each TAZ increases with the distance to the downtown area.

Figure 3 and Table 3 show the repartition of trips and speed statistics depending on the trip start time. Bicycle speeds remain stable over the day and show less variability than car speeds. The mean car speeds greatly decrease during rush hours. Figure 3 also shows that the distributions of speeds for each mode overlap: during morning and evening rush hours, the third quartile of the bike distribution is higher than the first quartile of the cars. 
Table 2 Distribution of the TAZs depending on the relative speed difference

\begin{tabular}{l|lllllllll}
\hline Relative speed difference & {$[0.0,0.2[$} & {$[0.2,0.4[$} & {$[0.4,0.6[$} & {$[0.6,0.8[$} & {$[0.8,1.0[$} & {$[1.0,1.5[$} & {$[1.5,2.0[$} & {$[2.0,3.0[$} & Non-significant \\
\hline Number of TAZs & 8 & 61 & 155 & 142 & 87 & 55 & 22 & 12 \\
Mean distance to downtown $(\mathrm{km})$ & 2.81 & 4.93 & 4.96 & 5.38 & 5.62 & 6.12 & 7.49 & 7.55 & 5.92 \\
\hline
\end{tabular}

4.93
5.38
5.62 
Table 3 Characteristics of trips depending on the period of the day

\begin{tabular}{|c|c|c|c|c|c|c|c|c|c|c|c|c|c|c|}
\hline \multirow{3}{*}{$\begin{array}{l}\text { Period } \\
12 \text { am to } 6 \mathrm{am}\end{array}$} & \multirow{2}{*}{\multicolumn{2}{|c|}{$\begin{array}{c}\text { Bikes } \\
\text { Number of trips }\end{array}$}} & \multirow{2}{*}{\multicolumn{2}{|c|}{$\begin{array}{c}\text { Cars } \\
\text { Number of trips } \\
\end{array}$}} & \multicolumn{5}{|c|}{ Bikes speed $(\mathrm{m} / \mathrm{s})$} & \multicolumn{5}{|c|}{ Cars speed (m/s) } \\
\hline & & & & & \multirow{2}{*}{$\frac{\mathrm{Q} 1}{3.4}$} & \multirow{2}{*}{$\frac{\mathrm{Q} 2}{4.5}$} & \multirow{2}{*}{$\frac{\mathrm{Q} 3}{5.6}$} & \multirow{2}{*}{$\begin{array}{l}\text { Mean } \\
4.4\end{array}$} & \multirow{2}{*}{$\frac{\text { Std }}{1.89}$} & \multirow{2}{*}{$\frac{\mathrm{Q} 1}{7.8}$} & \multirow{2}{*}{$\frac{\text { Q2 }}{10.4}$} & \multirow{2}{*}{$\frac{\text { Q3 }}{14.4}$} & \multirow{2}{*}{$\begin{array}{l}\text { Mean } \\
11.9\end{array}$} & \multirow{2}{*}{$\frac{\text { Std }}{6.27}$} \\
\hline & 636 & $0.8 \%$ & 2559 & $3.3 \%$ & & & & & & & & & & \\
\hline 6 am to $10 \mathrm{am}$ & 5158 & $6.6 \%$ & 12566 & $16.2 \%$ & 3.9 & 4.9 & 5.8 & 4.8 & 1.71 & 5.6 & 7.6 & 10.3 & 8.6 & 4.91 \\
\hline $10 \mathrm{am}$ to $3 \mathrm{am}$ & 3623 & $4.7 \%$ & 17450 & $22.4 \%$ & 3.3 & 4.4 & 5.3 & 4.2 & 1.81 & 5.8 & 8.1 & 10.5 & 8.9 & 5.09 \\
\hline $3 \mathrm{pm}$ to $8 \mathrm{pm}$ & 6832 & $8.8 \%$ & 22155 & $28.5 \%$ & 3.6 & 4.7 & 5.7 & 4.5 & 1.79 & 5.5 & 7.6 & 9.9 & 8.3 & 4.57 \\
\hline $8 \mathrm{pm}$ to $12 \mathrm{am}$ & 1301 & $1.7 \%$ & 5430 & $7.0 \%$ & 3.4 & 4.5 & 5.5 & 4.3 & 1.91 & 6.7 & 9.0 & 11.9 & 10.1 & 5.64 \\
\hline
\end{tabular}




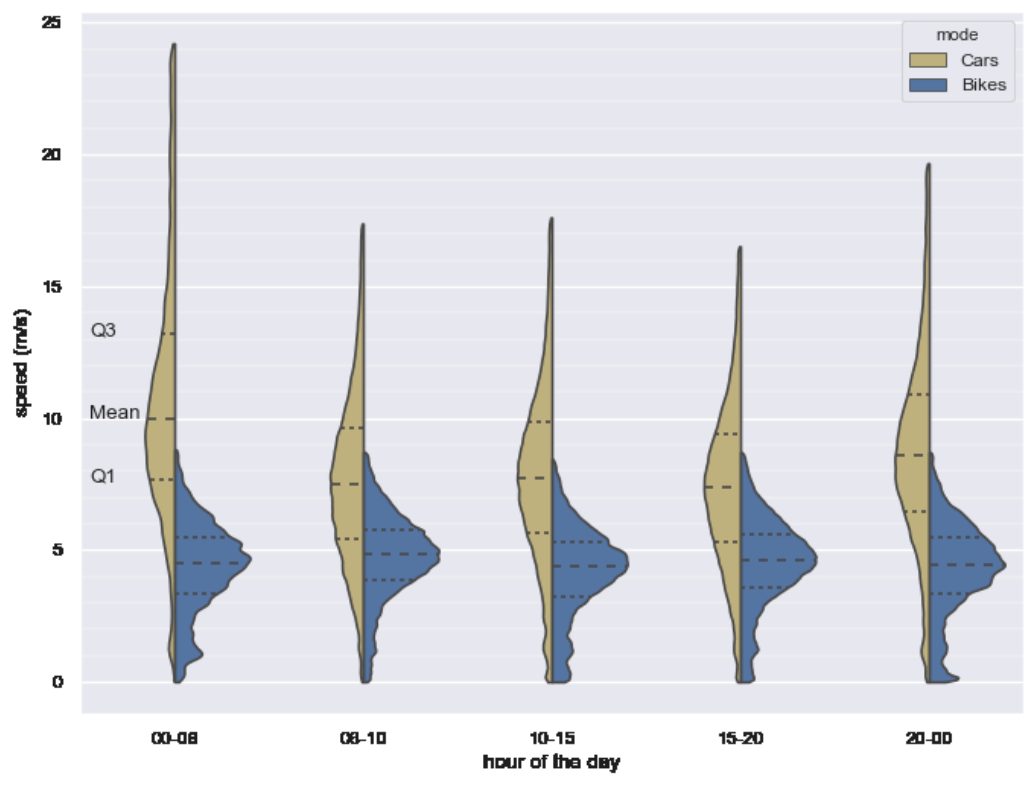

Figure 3 Distribution of trip's speed depending on the period of the day

As a final note, this study focused on speed and not one the overall travel time, which include also the time to find a parking and walk to one's final destination: higher car mean speeds do not necessarily translate into faster trips compared to bicycles. 


\section{REFERENCES}

Clarry, Andrew, Ahmadreza Faghih-Imani, and Eric J. Miller. 2019. "Where We Ride Faster? Examining Cycling Speed Using Smartphone GPS Data.” Sustainable Cities and Society 49 (August): 101594. https://doi.org/10.1016/j.scs.2019.101594.

Faghih-Imani, Ahmadreza, Sabreena Anowar, Eric J. Miller, and Naveen Eluru. 2017. "Hail a Cab or Ride a Bike? A Travel Time Comparison of Taxi and Bicycle-Sharing Systems in New York City." Transportation Research Part A: Policy and Practice 101 (July): 11-21. https://doi.org/10.1016/ j.tra.2017.05.006.

Jensen, Pablo, Jean-Baptiste Rouquier, Nicolas Ovtracht, and Céline Robardet. 2010.

"Characterizing the Speed and Paths of Shared Bicycle Use in Lyon." Transportation Research Part D: Transport and Environment 15 (8): 522-24. https://doi.org/10.1016/j.trd.2010.07.002.

McLeod, K., and E. Murphy. 2014. Where We Ride: Analysis of Bicycle Commuting in American Cities, League of American Bicyclists. League of American Bicyclists. https://bikeleague.org/sites/ default/files/Where_We_Ride_2014_data_web.pdf.

Mokhtarian, Patricia L., and Cynthia Chen. 2004. "TTB or Not TTB, That Is the Question: A Review and Analysis of the Empirical Literature on Travel Time (and Money) Budgets.” Transportation Research Part A: Policy and Practice 38 (9-10): 643-75. https://doi.org/10.1016/ j.tra.2003.12.004.

Vandenbulcke, Grégory, Claire Dujardin, Isabelle Thomas, Bas de Geus, Bart Degraeuwe, Romain Meeusen, and Luc Int Panis. 2011. "Cycle Commuting in Belgium: Spatial Determinants and 'ReCycling' Strategies.” Transportation Research Part A: Policy and Practice 45 (2): 118-37. https://doi.org/10.1016/j.tra.2010.11.004.

Ville de Montréal. 2019. “Déplacements MTL Trajet-CKAN.” http://donnees.ville.montreal.qc.ca/ dataset/mtl-trajet. 